\title{
3D Modelling in solution of cadastral and geodetic tasks
}

\author{
Polina Demidova ${ }^{1}$, Olga Kolesnik $^{1, *}$, and Hasan Al Fatin ${ }^{1}$ \\ ${ }^{1}$ Saint-Petersburg Mining University, Engineering geodesy Department, 199106, Saint Petersburg, \\ Russian Federation
}

\begin{abstract}
The main purpose of this study is demonstrating possibilities of using 3D modelling in solving scientific and practical problems et the field of geodesy and cadastre. Increasing number of publications on this topic among Russian and foreign authors are shown. The article considers examples of creating three-dimensional models for the purposes of cadastre and geodesy. A 3D model of cadastral registration of a complex object (gas station) in the specialized software ArchiCad together with Google Earth is presented. The composition of each stage and data set of each "step" of cadastral works in relation to such objects in Russian Federation are proposed. The article considers shortcomings of legal regulation in relation to $3 \mathrm{D}$ cadastre at the present stage. In addition, threedimensional models of the Dukan reservoir (Iraq), showing water levels at different times, were modelled. They based on digital data obtained from the digitized contour map. And it were used such software products like GlobalMapper, ArcMap and ArcScene. After analyzing the regulatory sources, conclusions about the lack of legal regulation in relation to the 3D cadastre in the Russian Federation were made.
\end{abstract}

\section{Introduction}

One of the recent technological innovations in geodesy and related sciences, in particular real estate cadastre, has been the active use of 3D modeling. At the moment, the role of upto-date information on real estate and natural resources is high. This information allows you to make the most complete and effective use of available resources and real estate objects. In addition, the quality of services for consumers increases.

\section{Materials and methods}

The unified state register of real estate (in Russian Federation) as an information system has up-to-date and complete information about real estate objects. However, a flat coordinate system is used for geodetic measurements of objects. It should be noted that this does not meet the conditions for correctly displaying complex spatial objects, such as transport interchanges, main underground pipelines, hydraulic structures, bridges, tunnels, subways,

${ }^{*}$ Corresponding author: Kolesnik_OA@pers.spmi.ru 
underground Parking lots, gas stations (hereinafter referred to as gas stations), communications, buildings overhanging roads [1-5].

Speaking of international experience, today the $3 \mathrm{D}$ inventory is used to some extent in 24 EU countries [6-11]. The validity is dictated by the increased need for modern updating of information, which will be achieved by switching to a three-dimensional representation of objects displayed on digital plans. The analysis of scientific papers in the scientific library elibrary.ru showed that over the past decade, interest in the three-dimensional inventory has increased dramatically in the Russian Federation, which also confirms the relevance of this study (table.1).

Table 1. Amount of publications by the topic "Three-dimensional cadastre" in the Russian Federation for 2010-2018

\begin{tabular}{|l|l|l|l|l|l|l|l|l|l|}
\hline Year & 2010 & 2012 & 2013 & 2014 & 2015 & 2016 & 2017 & 2018 & $\begin{array}{l}2010- \\
2018\end{array}$ \\
\hline $\begin{array}{l}\text { Quantity } \\
\text { of publi- } \\
\text { cations }\end{array}$ & 2 & 3 & 2 & 15 & 11 & 16 & 19 & 35 & 103 \\
\hline$\%$ & 1.9 & 2.9 & 1.9 & 14.6 & 10.7 & 15.5 & 18.4 & 34.0 & 100.0 \\
\hline
\end{tabular}

As for hydraulic structures and water resources, in recent years there has been a similar increase in research based on 3D modeling [12-13]. For example, one of the most important factors affecting the effectiveness of dams is the water level in the dam's reservoir. There is a direct relationship between the water level and the horizontal movement of the dam body. Therefore, water level monitoring should be continuous, and observations should be made daily, monthly, and annually. The most convenient and modern way to achieve this goal is $3 \mathrm{D}$ modeling.

In this study, we will consider two completely different objects from the point of view of 3D modeling for the purposes of cadastre and geodesy: a gas station and a water object (reservoir). And we will creating three-dimensional models for them using different functionality.

The gas station consists of buildings and structures located separately on the land plot: a control room, a capital shed, and fuel tanks. Fig. 1 shows an example of the gas station location, the main purpose of it is to serve the population by offering a service for filling cars with fuel. All objects (movable and immovable) in it are united by this idea and aimed at achieving this goal.

The gas station is a single real estate complex, since the objects on the territory of the development are connected by a common purpose and are located on the same territory. At the same time, following the current legislation, detailed display of components - movable and immovable elements of gas stations is not regulated. In addition, the requirements of customers and registration authorities for cadastral registration differ: in some cases, only the operator's building is registered, in others-the operator's building and the shed. In reality, everything depends on the customer of cadastral works and the task for carrying out accounting works and on what acts the cadastral engineer will use when carrying out these works. Similar patterns apply to asphalt pavement - whether it will be displayed on the plan or not. 


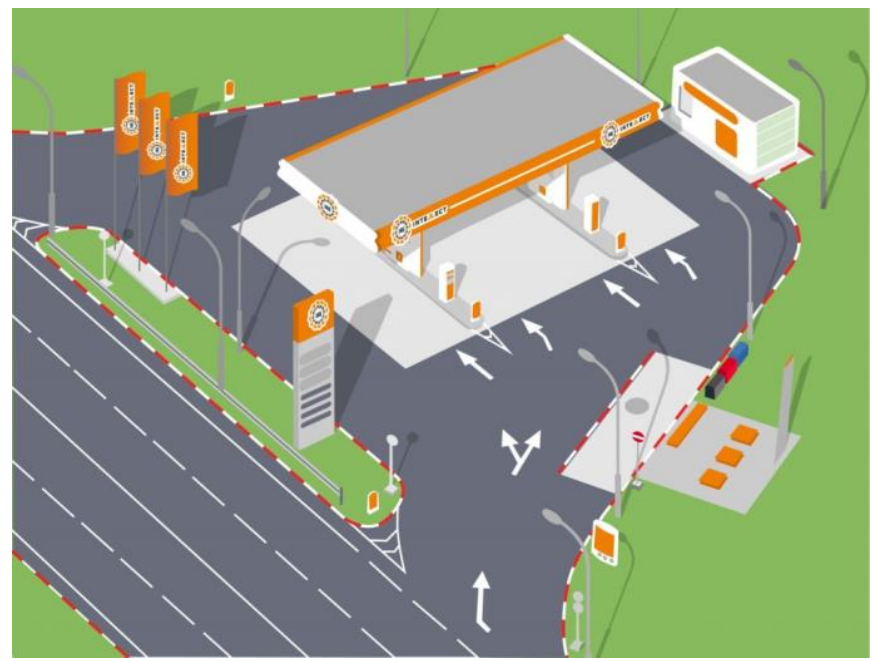

Fig. 1.Scheme of the gas station

The next object is the Dukan reservoir (Fig. 2). The Dukan dam and its reservoir are located on the Maly Zab river, one of the important tributaries of the Tigris river in NorthEastern Iraq. The dam is multi-purpose (storage for flood control, hydropower and irrigation). It is the oldest dam in Iraq and it has been in operation since 1959. The catchment area is 11,690 sq. km. The surface Area of the reservoir is $270 \mathrm{sq} . \mathrm{km}$. [14-16].

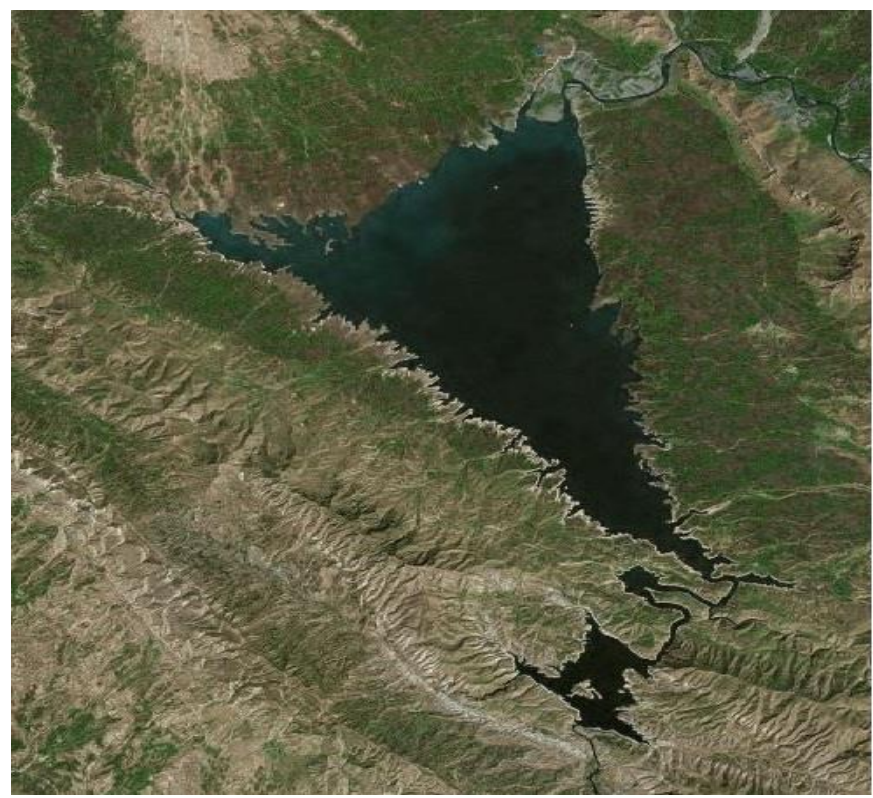

Fig. 2. Satellite image of the Dukan reservoir (2D model)

It is worth noting that it is difficult to choose a single model for displaying all types of objects in the surrounding world, since the natural environment is complex and the objects are located at different levels, have different shapes, different functional purposes, and consist of different materials. This circumstance determines the need to classify 3D models. For example, by the following characteristics:

- $\quad$ class (virtual and real 3D models); 
- method of 3D modeling of spatial objects (volumetric representation, method of structural solid geometry, planar representation, extrusion method; representation using borders;

- level of detail (two-dimensional contours of buildings; blocks, flat roof; textures, real roof; complex architectural elements; interior model);

- dimension of the object (taking into account the vertical direction-z coordinates at a given point ( $\mathrm{x}, \mathrm{y})$, time interval, scale);

- $\quad$ visibility and realism of the model (selection of necessary materials and textures).

The most common in cadastral systems today are virtual 3D models created using the boundary representation method, which are easily processed using modern software.

There are several options for developing software for 3D inventory purposes:

- development of fundamentally new software products taking into account the requirements of the three-dimensional inventory;

- merging software products (for example, a public cadastral map with the ArchiCad program, which is in demand in the 3D model market, and then developing a semantic information module);

- development and adaptation of software systems used in the three-dimensional inventory of foreign countries, as well as Google software products, to the conditions of Russia.

Drawing up a technical plan for cadastral registration of gas stations is still one of the most unresolved issues in the legislation of the Russian Federation. Since there are no direct instructions for setting the gas station object as a single real estate complex, at the moment the gas station is being registered by drawing up and submitting a technical plan of the structure to the cadastral registration authority. The construction plan specifies the components of the gas station.

Turning to the question of how to produce a design object filling stations, should pay attention to the Order of Ministry of economic development of the Russian Federation №953 of 18.12.2015 "About approval of the form of the technical plan and requirements to its preparation, the composition of contained information and Declaration form about the property and requirements for its preparation, composition of the contained information".

According to paragraph 21 of section II of this Order "General requirements for the preparation of a technical plan": "if the location of a building, structure or object under construction at the request of the customer of cadastral works is additionally set by means of a spatial description of structural elements of a building, structure or object under construction, the Annex includes a model of such a building, structure, object under construction, containing a spatial description of its structural elements, including taking into account the height or depth of such structural elements, in the form of an electronic document in one of the formats: DXF, RVT, PLN, SKP (hereinafter-the 3D model of the real estate object), which is certified by a strengthened qualified electronic signature of the cadastral engineer who prepared the technical plan".

Following section III, Paragraph 40 "Requirements for the design of the text part of the technical plan", of this order-a spatial description of the accounting object structural elements is made, as well as the conditions for including 3D model in the application are mentioned:

- 1:1 scale;

- coordinate reference to the State Geodetic Network or reference boundary network.

In the section "Description of the location of a real estate object", the distance from the point of intersection of the projection of a structural element with the contour of such a building, structure, or unfinished construction object (hereinafter - H0) to the point of origin of such a structural element of a building, structure, or unfinished construction at this 
characteristic point of the contour (hereinafter - depth, height, or H1) is specified in meters rounded to 0.1 meters. In the same section, the distance from $\mathrm{H} 0$ to the end point of such a structural element of a building, structure, or object under construction at this characteristic point of the contour (hereinafter referred to as depth, height, or H2) is specified in meters rounded to 0.1 meters."

The definition of the characteristic points of the canopy (structural element) of the gas station is shown in Fig. 3.

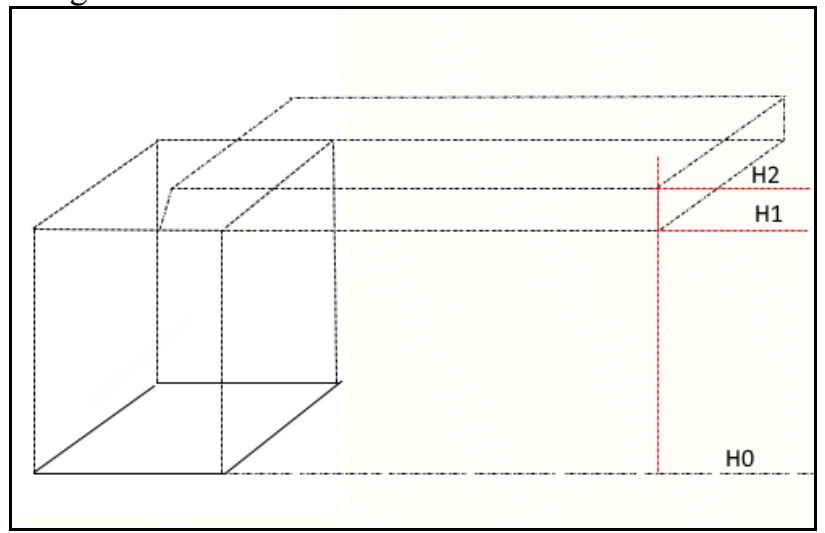

Fig. 3. Determination of the gas station structural element height

Following the concept of spatial accounting, all elements of the station will be displayed later, with the exception of information stands. If it is clear that turning points are being coordinated in relation to the operator's building and the shed, the same cannot be said for storage facilities and fuel communications. We assume that the coordinates of the gas and gas pipeline will be determined using a tracer. The position of the fuel tanks is determined by the coordinates of the outlet holes of the tanks. Knowing these coordinates of the holes and using the design documentation, it is possible to locate underground reservoirs in three dimensions X, Y, and z Inside the software, for example, in AutoCad.

ArchiCad was chosen as a computer-aided design system for the gas station under consideration. As you know, ArchiCAD is a computer-aided design system designed for modeling architectural objects. One of its advantages is that ArchiCad interacts with GoogleEarth. This gives you the following features: binding to Earth coordinates in the GoogleEarth environment at the design stage, which definitely helps when visualizing the project. Thanks to Google EarthConnections, you can easily get aerial photos of the area and other data from the Google Earth environment and use it within the project, for example, to build terrain. To Orient an object in the GoogleEarth system, you need to know the $\mathrm{x}$ and $\mathrm{Y}$ origin of the ArchiCad coordinates in the WGS-84 coordinate system and the value of the angle between the North and base direction.

Note that a more accurate and convenient way of 3D modeling is to simulate using survey files of various formats (dwg, dxf, etc.) or via uploaded cadastral XML schemas of the location of land plots and capital construction objects from the Rosreestr website by requesting information. The digital data bases of the formats are converted to the KML format(an XML-based markup language for representing three-dimensional geospatial data in Google Earth) in three planes. This functionality allows you to integrate 3D models into KML, but only for authorized users, software developers of this platform. This method is more reliable and accurate than the previous method, which specifies the project start and the angle between the North direction and the project baseline. If you specify an angle, a high measurement error is possible, which will affect the offset of all points in the property model. 
As for the representation of the reservoir in three-dimensional form, the most suitable method is a planar representation. It describes curved surfaces by approximating them with a certain number of triangular or quadrangular plates (triangulation).

In this part of the study, we used topographical data from the Dukan dam reservoir to create TIN and DEM, which are used to create 3D models in Arc Scene for reservoirs with different water levels. Observations were made by a regular sensor that recorded changes in the water level in the lake every day. Based on the 3D model of the reservoir, we can draw a conclusion for monitoring the water level that affects the deformation of the dam, representing different water levels over a certain period of time. We can calculate the volume of water in the reservoir at each water level at any time and determine the amount of water pressure of the dam, from which we can determine what level of water is dangerous for the dam.

\section{Results}

As a result of the research conducted on the first object under consideration, a 3D model of the gas station in ArchiCad was obtained (Fig.4).For the second object under consideration, a digital model was created using digital data extracted from the digitized contour map of the dam reservoir, which is used to model three-dimensional models showing water levels at different times (Fig.5-7)

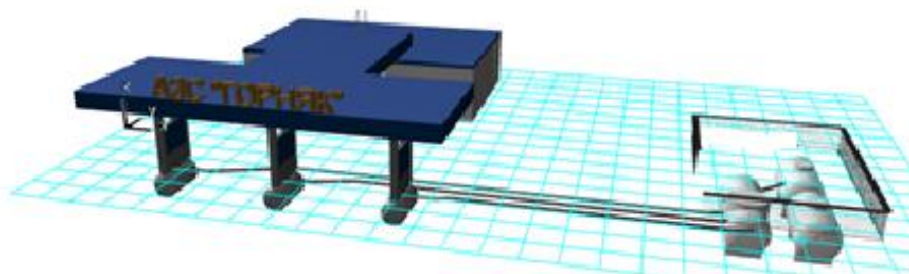

Fig. 4. Gas station model in ArchiCad

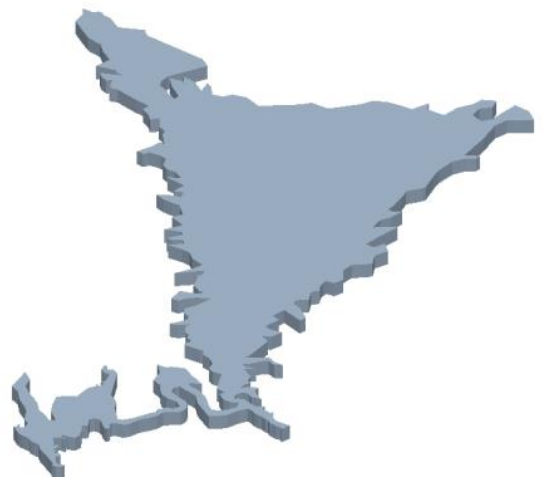

Fig. 5. 3D-model of the Dukan reservoir, built using ArcMap and ArcScene (water level $500 \mathrm{~m}$ ) 


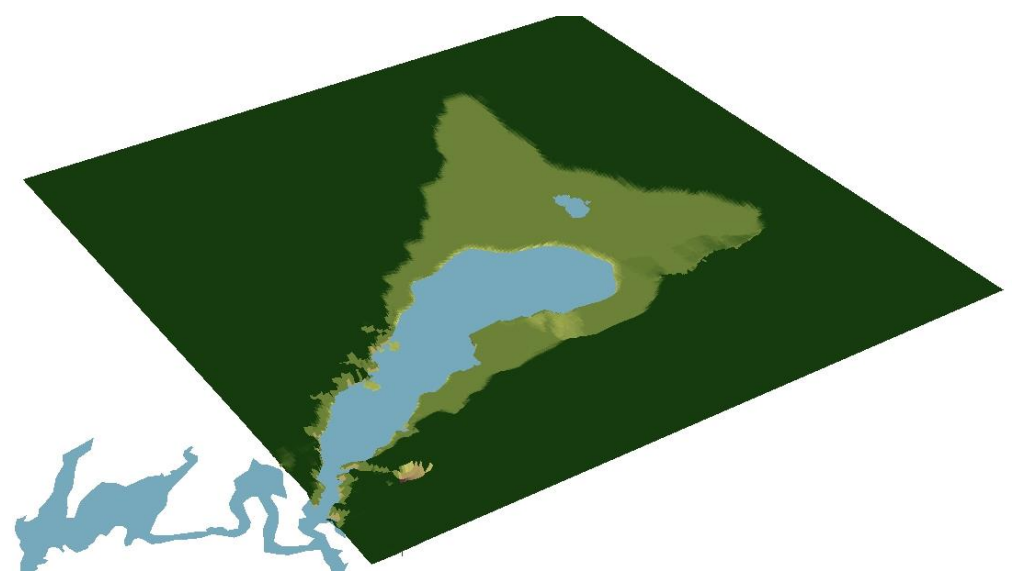

Fig. 6. 3D-model of the Dukan reservoir, built using ArcMap and ArcScene (water level $470 \mathrm{~m})$

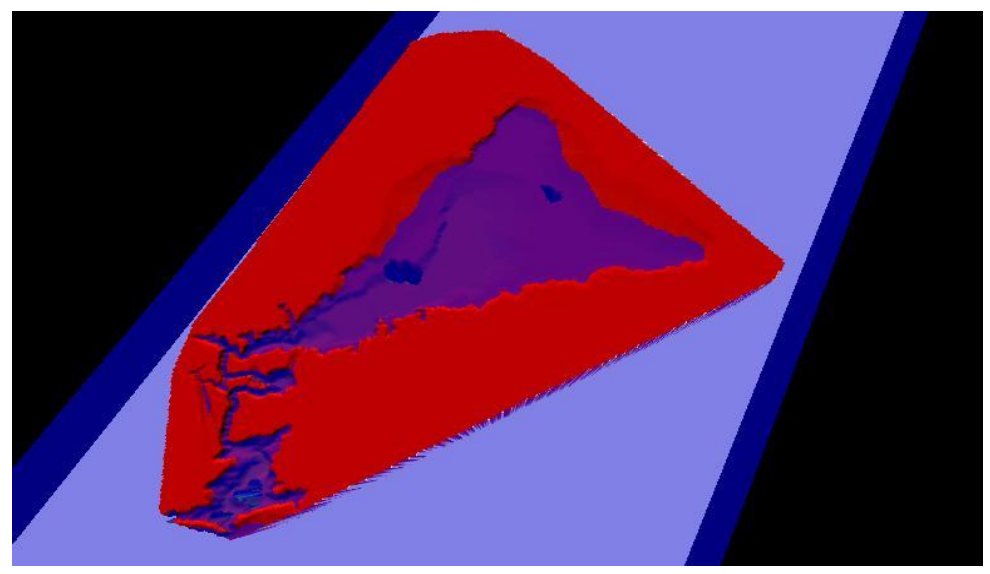

Fig. 7. 3D-model of the Dukan reservoir, built using Global Mapper (water level $470 \mathrm{~m}$ )

\section{Discussion}

For fig. 6 the green zone is represented upstream from the dam, and the water level was $470 \mathrm{~m}$, which is lower than the level in Fig.5, which was $500 \mathrm{~m}$. Fig. 7 shows a model built using Global Mapper. This program can show a clear model with the water surface at any level. The models in Fig.5-7 helps to know the volume of water and determine the danger caused by water pressure on the body of the dam. This is a fairly quick way to monitor the water level in the reservoir and determine the level that ensures the stability of the dam. Using information monitoring of the horizontal movement of the dam body and at the same time monitoring the water level, it is possible to determine the maximum safe level that water can reach in the event of an emergency without causing any harm to the dam.

\section{Conclusions}

As can be seen, including from the study, three-dimensional modeling in cadastral and geodetic works is gaining popularity due to the fact that the resulting models are clear and highly effective in terms of forecasting possible scenarios. However, three-dimensional 
modeling for the purposes of the inventory is at an early stage of development. After analyzing the regulatory sources, we made the following conclusions about the lack of legal regulation in relation to the $3 \mathrm{D}$ cadastre in the Russian Federation: - there is no unambiguity in the form of the application of documents containing spatial 3D models of objects; - there are no spatial symbols, but if it is intended to use 2D symbols for displaying objects, then there are no indications about this; - there is no categoricity for creating spatial models in the register of "complex objects", since in our time this condition is met only if the customer wants the work. This requirement would reduce uncertainty when displaying objects on the map, reduce errors when overlaying and positioning real estate objects.

\section{References}

1. M.G. Mustafin, H.V. Nguen, Geodesy and Cartography, Assessment of vertical displacements of the foundations of buildings and structures based on the analysis of the elements of the deformation network, 80(3), 11-19 (2019) https://doi.org/10.22389/00167126-2019-945-3-11-19

2. D.V. Beregovoi, J.A. Younes, M.G. Mustafin, Procedia Engineering, Monitoring of quarry slope deformations with the use of satellite positioning technology and unmanned aerial vehicles, 189, 737-743 (2017) https://doi.org/10.1016/j.proeng.2017.05.116

3. A.A. Kuzin, V.A. Valkov, A.I. Kazantsev, J. of Physics: Conference Series, Satellite-based techniques for monitoring of bridge deformations, 1118(1), 1-6 (2018)https://doi.org/10.1088/1742-6596/1118/1/012022

4. N. Vandysheva, V. Tikhonov, P. van Oosterom, J. Stoter, H. Ploeger, R. Wouters, V. Penkov, FIG Working Week 2011, 3D Cadastre Modelling in Russia, (2011) https://www.researchgate.net/publication/241886547_3D_Cadastre_modelling_in_Russia

5. P.A. Demenkov, L.A. Goldobina, O.V. Trushko, Journal of Mining Institute, The method of predicting the deformation of the earth's surface when constructing pits under conditions of dense urban development using the "wall in soil" method,233, 480-486 (2018)https://doi.org/10.31897/PMI.2018.5.480

6. J. Stoter, S. Ho, F. Biljecki, Considerations for a contemporary $3 D$ cadastre for our times, (2019)https://doi.org/10.5194/isprs-archives-XLII-4-W15-81-2019

7. U. Gruber, J. Riecken, M. Seifert, Germany on the way to 3D-cadastre (2014) https://doi.org/10.12902/zfv-0028-2014

8. N. Vučić, M. Mađer, S. Vranić, M. Roić, Land Use Policy, Initial 3D cadastre registration by cadastral resurvey in the Republic of Croatia (2020) https://doi.org/10.1016/j.landusepol.2019.104335

9. K.H. Fahad, IOP Conf. Ser.: Mater. Sci. Eng., Spatial-Temporal Analysis of Land Use and Land Cover Change Detection Using Remote Sensing and GIS Techniques, 671 $012046(2020)$

10. H. Dibs, S. AL-Hedny, H. Karkoosh, IJCIET, Extracting detailed buildings $3 d$ model with using high resolution satellite imagery by remote sensing and GIS analysis, 9(7), 1097-1108 (2018)

https://www.researchgate.net/publication/326772084 extracting detailed buildings $3 \mathrm{~d}$ model with using high resolution satellite imagery by remote sensing and gis analy sis al-qasim green university a case study

11. W. Hua, M. Hou, Y. Hu,. ISPRS Annals of the photogrammetry, Remote sensing and spatial information sciences, Review of $3 d$ GIS data fusion methods and progress, IV3(2018) https://doi.org/10.5194/isprs-annals-IV-3-121-2018 
12. M. Khattab, R. Abo, S. Al-Muqdadi, B. Merkel, Scientific Research Publishing, Advances in Remote Sensing, Generate reservoir depths mapping by using digital elevation model. A Case Study of Mosul Dam Lake, Northern Iraq,6, 161-174 (2017)https://doi.org/10.4236/ars.2017.63012

13. S. Khemiri, I.Chenini, S. Saidi, B. Baamar, A. Mammou, Scientific Research Publishing, Journal of Water Resource and Protection, DEM-Based GIS algorithms and 3D geospatial mapping for creation of hydrogeological models data in Foussana Basin (Central Tunisia), 5(8), 801-815 (2013) https://doi.org/10.4236/jwarp.2013.58081

14. V. Sissakian, A. Abdulahad, N.A. Al-Ansari, R. Hassan, S. Knutsson, J. Earth Sci. Geotech. Eng, The regional Geology of Dokan Area, NE Iraq,6(3), 35-63 (2016)https://www.researchgate.net/publication/301607789 The Regional Geology of D okan Area NE Iraq

15. Rebwar H, Ali A., Hazim A., Al-Ansari N., Knutsson S., Reduction in the Storage Capacity of Dokan Dam Reservoir, (2019) https://doi.org/10.1007/978-3-030-01572-5 101

16.R. Hassan, N.A. Al-Ansari, A.A. Ali, S.S. Ali, S. Knutsson, J. Lakes Reserv.: Res. Manag, Bathymetry and siltation rate for Dokan Reservoir, Iraq,20(2), 1-11 (2017)https://doi.org/10.1007/978-3-030-01572-5_101 